\title{
The locus of forgetting of words and trigrams ${ }^{1}$
}

\author{
STEVEN L. HACKBARTH \\ ANDRE, ${ }^{2}$ Sacramento State College, \\ Sacramento, Calif. 95819
}

Ninety-two Ss learned a word-response (r) paired-associate (PA) list, and 92 different Ss learned a consonant-syllable (CCC) $r$ PA list. Three types of recall tasks were given prior to the final recall test in order to determine the locus of forgetting for naive Ss after a retention interval of $24 \mathrm{~h}$. For the word list, $r$ presentation facilitated final recall, indicating that an important locus of forgetting was loss of $r$ availability. For the $C C C$ list, $r$ presentation was not effective over appropriate controls. Stimulus (s)-r recall was found to be nearly equal to $r$-s recall for the word $r$ group, however, inferior to $r$-s recall for the CCC $r$ group. Repeated recall trials without informative feedback generally facilitated recall of both lists.

The locus of forgetting as a function of meaningfulness has been a subject of intense study. Underwood \& Postman (1960) postulated that proactive inhibition from previously learned natural language habits should differentially affect the retention of lists varying in meaningfulness. Studies failing to give strong support to these postulated sources of interference include: Ekstrand \& Underwood, 1965; Postman, 1961, 1962a, b; Underwood, 1964; and Underwood \& Postman, 1960. Underwood (1966) therefore concluded that if lists differing widely in difficulty of learning are taken to the same degree of learning, we may expect that after $24 \mathrm{~h}$, retention of both lists will be the same.

The possibility still exists that the locus of forgetting might be different for such lists. A constant loss at $24 \mathrm{~h}$ might well be due to the postulated effects of natural language habits on $r$ availability and on association between $\mathrm{s}$ and $\mathrm{r}$ as a function of meaningfulness. In the present study, rs are provided prior to a final recall test in an effort to determine the extent to which loss of $\mathrm{r}$ availability affects recall.

\section{METHOD}

A total of 184 college students, naive to verbal learning experiments, were divided into two separate groups. One group learned a word r PA list, and the other learned a CCC r PA list. The eight ss and the first letter of the corresponding rs were selected from nine pairs as used by Underwood (1964). The rs for the word list were three-syllable nouns selected from Thorndike \& Lorge (1944) for their high frequency of occurrence (X.Favorite,
I-Government, J-Happiness, E-Quality, B-Juvenile, Q-Company, V-Kerosene, W-Position). The rs for the trigram list were CCCs beginning with the preselected first letter. Four of the CCCs were selected from Witmer (1935) for low association strength. The other four were either the first-or second-most difficult to pronounce of those listed by Underwood \& Schulz (1960) with the preselected first letter (X-FCM, I-GVS, J-HTF, E-QZG, B-JXQ, Q-CKB, V-KBR, W-PJZ). All rs were chosen to insure a minimum of intralist similarity.

Each S completed the alternate study-recall learning trials individually on the first day for which he volunteered. The list was presented at a 3:3 rate, in three random study and three random recall orders, on a Stowe, Model 459B, memory drum until $\mathbf{S}$ performed one errorless recall trial. Since Underwood (1964) rightly states that it is presently impossible to equate degree of original learning at such high levels, no direct comparisons were planned between lists; however, every effort was made to make the two sets of data as comparable otherwise as possible.

Each of the two groups was then divided into four equal, independent groups $(\mathrm{N}=23)$ on the basis of sex and trials to criterion to insure a minimum of variation in the acquisition stage between groups. The four groups were control (C), asterisks presentation (AP), s presentation (SP), and r presentation (RP). Each $S$ returned after a retention interval of $24 \mathrm{~h}$. Each $\mathrm{C}$ group $S$ received an immediate paced (3:3 rate) recall test in order to determine a base measure of retention. This final recall test was the same for all groups. Each AP group $S$ received a series of paced recall trials without informative feedback. S was asked to attempt to recall the s-r pairs as the drum presented rows of asterisks for the equivalent of five recall trials. This was to insure that $S$ used the time in an effort to retrieve correct rs. AP served as a control for the $\mathrm{SP}$ and $\mathrm{RP}$ treatments by separating the effect of simply allowing $S$ sufficient time to arrive at correct rs in the presence of contextual cues, from the effect of actually presenting list ss or rs. Each SP group $S$ received a series of five paced recall trials without feedback as to the association between s-r pairs. $S$ was asked to recall the s-r pairs as the drum presented the list ss with asterisks in the place of the list rs. Each RP group $S$ received a series of five paced recall trials without feedback as to the association between s-r pairs. $S$ was asked to attempt to recall the s-r pairs (in that order) as the drum presented the list rs with asterisks in the place of the list ss. A 30-sec break immediately following each treatment allowed $\mathrm{E}$ to give the final recall instructions before proceeding to the final recall test, which immediately succeeded the treatment trials on a continuous tape.

\section{RESULTS AND DISCUSSION}

The word $r$ list required an average of eight trials to learn, while the CCC $\mathrm{r}$ list required an average of 41 trials, clearly demonstrating the effect of $r$ meaningfulness on PA list learning.

Recall scores consisted of the number of fully correct rs given on the final test trial after the 24-h retention interval. The means $(\overline{\mathrm{X}})$ and standard deviations (s) for each group are presented in Table 1. Per cent recall is presented in parentheses.

A one-way analysis of variance for the word $r$ groups was significant, $F(3,88)=3.32, p<.025$. The C, AP, and SP group means were identical. Recall for the RP group was significantly better than for the $\mathrm{C}, \mathrm{AP}$, and SP groups pooled, $t(88)=3.16, p<.01$. This indicates that an important locus of forgetting was loss of word $r$ availability in the experimental context, and was consistent with an interference theory in terms of the extensive use of the high-frequency words in extraexperimental contexts.

The one-way analysis of variance for the CCC groups was significant, $F(3,88)=3.10, p<.05$. The AP, SP, and RP groups performed similarly, and when they were pooled, their recall was significantly better than that of the $\mathrm{C}$ group, $t(88)=2.80, p<.01$. Repeated recall trials without informative feedback had a facilitory effect on the recall of CCC responses. Considering the complexity of the CCC rs, it was most surprising that actual I presentation did not facilitate Table 1 24 Hour Recall

\begin{tabular}{|c|c|c|c|c|}
\hline & \multicolumn{4}{|c|}{ Treatments } \\
\hline & $\mathrm{C}$ & $\mathrm{AP}$ & SP & $\mathbf{R P}$ \\
\hline \multicolumn{5}{|c|}{ Words } \\
\hline$\overline{\mathrm{X}}$ & $6.87(86 \%)$ & $6.87(86 \%)$ & $6.87(86 \%)$ & $7.61 \quad(95 \%)$ \\
\hline s & 1.01 & 1.14 & 1.01 & 0.66 \\
\hline \multicolumn{5}{|c|}{$\mathrm{CCCs}$} \\
\hline$\overline{\mathrm{X}}$ & $5.43(68 \%)$ & $6.22(78 \%)$ & $6.43(80 \%)$ & $6.78(85 \%)$ \\
\hline $\mathbf{s}$ & 1.97 & 1.51 & 1.47 & 1.16 \\
\hline
\end{tabular}


greatly the recall of the RP group over the AP and SP groups. Groninger (1966) suggested that a trigram plus its natural language mediator was a new verbal entity with relative uniqueness and power to resist the interfering effects of prior items. Perhaps the use of overlearned mediators in the acquisition stage made the letter-sequence interference hypothesis less applicable to $\mathrm{CCC}$ rs than was originally proposed.

There was virtually no difference between AP and SP group final recall for either word or CCC $r$ lists. The five successive AP trials were, in effect, similar to free recall, and for both types of lists, the mean number of s-r pairs given correctly at least once during these trials was identical to the mean number of correct responses during the final paced trial in which the ss were presented. This calls into question the importance of list $s$ cueing and suggests that a more general form of contextual cueing might be sufficient for $\mathrm{s}$ as well as for $\mathrm{r}$ recall.

Performance on the five successive recall trials was plotted for the SP and RP word response groups in Fig. 1. Scores for the SP group consisted of the number of rs correctly recalled on each trial, while scores for the RP group consisted of the number of ss correctly recalled on each trial.

Forward, s-r, recall was nearly identical to backward, r-s, recall over all five trials. There was a slight, but significant, rise in $s-r$ as well as in $r-s$ recall from Trial 1 to Trial 5, $\mathrm{t}(22)=2.15, \mathrm{p}<.05$ and $t(22)=2.07, p<.05$, respectively. The percentage of Ss increasing, decreasing, or

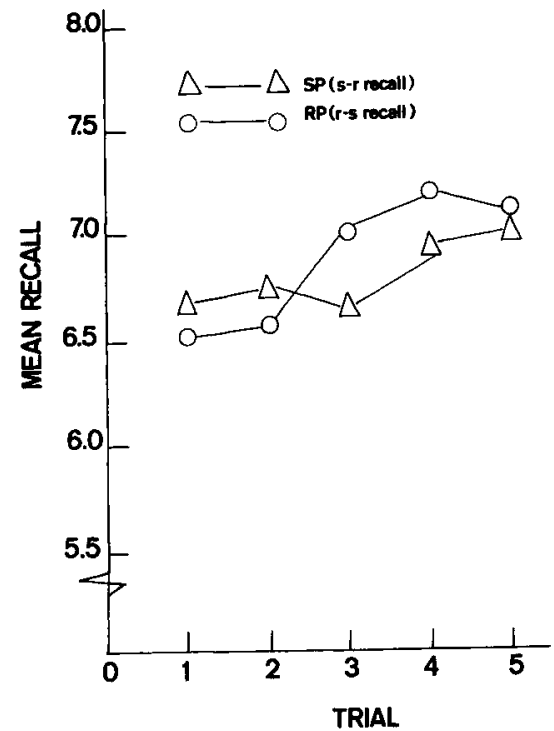

Fig. 1. Repeated recall trials for the word $r$ PA list, SP and RP groups. unchanging from Trial 1 to Trial 5 was 43-13-43 for each of the groups.

Performance on the five successive recall trials was plotted for the SP and RP CCC r groups in Fig. 2.

For the CCC $\mathrm{r}$ list, s-r recall was clearly inferior to $r-s$ recall over all five trials. It was more difficult to retrieve and pronounce the correct $\mathrm{CCC}$ rs in the time given than to retrieve and pronounce the correct single-letter ss. The rise from Trial 1 to Trial 5 approached significance for s-r recall, $\mathrm{t}(22)=1.74,0.05<\mathrm{p}<.10$, and was significant for $r-s$ recall, $t(22)=2.32, p<.05$. The percentage of Ss increasing, decreasing, or remaining the same was 43-17-39 for the SP group and 35-9-56 for the RP group.

The only methodological difference between $C$ recall and Trial $1 \mathrm{SP}$ recall was that the $\mathrm{C}$ group had been informed that they were going to have just one final recall trial, while the SP group had been informed that they were going to have five warm-up trials prior to the recall test. There was no significant difference between $\mathrm{C}$ and Trial $1 \mathrm{SP}$ recall for words, $\mathrm{t}(44)=0.90, \quad$ or $\mathrm{CCCs}, \mathrm{t}(44)=0.62$ (nonorthogonal comparisons), attesting to the comparability of the $C$ groups with the SP experimental groups prior to treatment.

The increments over repeated recall trials for both lists seem to be about the same in absolute value as well as significance. The effect was small and would probably not be detected in anything but a repeated Ss analysis in which individual $S$ variability is removed, or when a very large number of Ss are employed in independent groups, as in the

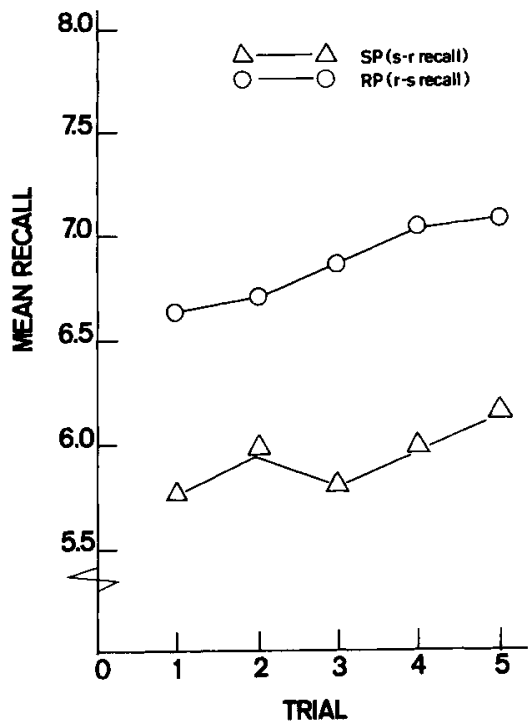

Fig. 2. Repeated recall trials for the $\mathrm{CCC}$ r PA list, SP and RP groups.
CCC analysis where the three repcated recall groups were combined before comparison with $\mathrm{C}$. The percentage data indicate that the significant rise was a characteristic of a relatively large percentage of $S s$ independent of type of recall or type of list.

Other studies showing an increase in correct rs during "extinction" trials after a long retention interval include Richardson (1958, 1960) and Wollen (1962). Adams (1967) suggests that ". . it is possible that warm-up might be a factor in experiments of the type that use relatively long retention intervals [p. 297]." However, the increment with repeated recall trials also occurs immediately following learning (Goss, Morgan, \& Golin, 1959; and Goss, Nodine, Gregory, Taub, \& Kennedy, 1962), where warm-up would supposedly not be a factor. Rather than warm-up in the physical and attentive sense, the senior author suggests that the increment in both types of studies is due to a more active process of retrieval on the part of a certain percentage of the Ss.

It is interesting that the combined experimental $\mathrm{CCC} r$ groups performed significantly better on the final recall than did the $C$ group. Richardson (1958) found a tendency for his more difficult lists to make greater gains than the easier lists over five recall trials. Further research will have to determine if, perhaps, a greater latency in responding with difficult lists further augments the facilitative effect of repeated recall trials beyond that found with easier lists.

\section{REFERENCES}

ADAMS, J. A. Human memory. New York: McGraw-Hill, 1967

EKSTRAND, B. R., \& UNDERWOOD, B. J. Free learning and recall as a function of unit-sequence interference and letter-sequence interference. Journal of Verbal Learning \& Verbal Behavior, 1965, 4, 390-396.

GOSS, A. E., MORGAN, C. H., \& GOLIN, S. J. Paired-associates learning as a function of percentage of occurrence of response members (reinforcement). Journal of Experimental Psychology, 1959, 57, 96-104.

GOSS, A. E., NODINE, C. F., GREGORY, B. N., TAUB, H. A., \& KENNEDY, K. E. Stimulus characteristics and percentage of occurrence of response members in paired-associate learning. Psychological Monographs, 1962, 76, 12, Whole No. 531

GRONINGER, L. D. Natural language mediation and covert rehearsal in short-term memory. Psychonomic Science, 1966, 5, 135-136.

POSTMAN, L. Extraexperimental interference and the retention of words. Journal of Experimental Psychology, 1961, 61, 97-110.

POSTMAN, L. The effects of language habits on the acquisition and retention of verbal associations. Journal of Experimental Psychology, 1962a, 64, 7-19.

POSTMAN, L. Repetition and paired associate learning. American Joumal of Psychology, $1962 b, 75,372-389$.

RICHARDSON, J. The relationship of stimulus 
similarity and number of responses. Journal of Experimental Psychology, 1958, 56, 478-484.

RICHARDSON, J. Association among stimuli and the learning of verbal concept lists. Journal of Experimental Psychology, 1960 60, 290-298.

THORNDIKE, E. L., \& LORGE, I. The teacher's word book of 30,000 words. New York Bureau of Publications, Teachers College, Columbia University, 1944.

UNDERWOOD, B. J. Degree of learning and the measurement of forgetting. Joumal of Verbal Learning \& Verbal Behavior, 1964, 3, 112-129.

UNDERWOOD, B. J. Experimental psychology. (2nd ed.) New York: Appleton-CenturyCrofts, 1966

UNDERWOOD, B. J., \& POSTMAN, L. Extraexperimental sources of interference in forgetting. Psychological Review, 1960, 67, 73-95.
UNDERWOOD, B. J., \& SCHULZ, R. W Meaningfulness and verbal learning. New York: Lippincott, 1960.

WITMER, L. $R$. The association value of three-place consonant syllables. Journal of Genetic Psychology, 1935, 47, 337-360.

WOLLEN, K. A. One-trial versus incremental paired-associate learning. Journal of Verbal Learning \& Verbal Behavior, 1962, 1, 14-21.

\section{NOTES}

1. Based on an MA thesis submitted to Sacramento State College under the direction of the junior author.

2. Senior author now at Southwest Regional Laboratory for Educational Research and Development, 11300 La Cienega Blvd. Inglewood, Calif. 90304.

\section{The effect on word recall when storage and retrieval cues differ}

\begin{abstract}
ROBERT L. HUDSON and E. JOYCE REYNOLDS, Mississippi State University, State College, Miss. 39762
\end{abstract}

Ss were presented 32 stimulus words from the Underwood \& Richardson (1956) norms over six presentation-recall trials. The independent variable was the trial of presentation of retrieval information in the form of category names. These were presented between presentation and recall on Trials 2, 4, or 6 for the three experimental groups. Two control groups were also used; one was presented the category information before recall trials started, and one was never presented the information. The major finding was a decreased recall on trials in which the information was presented. Also, category clustering increased on trials subsequent to the information trial, but number of words recalled did not differ from the control group on subsequent trials.

Earhard (1969) gave Ss several presentation-free recall trials with a list of unrelated words. The major independent variables she manipulated were the trial and the point in the trial (either before the presentation or between presentation and recall) in which the Ss were asked to recall the words in alphabetical order. She reasoned that the more trials an $S$ had with his subjective storage-retrieval system, the larger the recall decrement would be when the $S$ was asked to change the system to one of alphabetical recall. She also hypothesized that there would be a larger decrement if the instructions to recall alphabetically were given immediately following a presentation rather than immediately preceding a presentation. These hypotheses were based on the assumption that Ss store words in some manner such that the several words are functionally dependent rather than completely independent. Her hypotheses were supported.

Hudson (1969) reported a similar study where words from the Underwood \& Richardson (1956) norms were used as stimuli. The Ss were presented 32 words, eight from each of four categories, and were asked for a single recall after four presentations. The major independent variable was locus of instructions concerning the fact that the words could be categorized along with the category names. The information-before (IB) group was given the instructions before the presentations began, the information-after (IA) group was given the information after the fourth presentation, which was immediately before recall. The no-information (NI) group was given no indication that the words could be categorized. The major findings were that the IB and NI groups did not differ in number of words recalled but that both were significantly superior to the IA group. It was also found that the IB group had a significantly higher clustering index than either the IA group or the NI group, between which there was no difference. Hudson (1969) interpreted these findings as indicating that retrieval information must be stored with the target words in order to be effective, which is in line with the hypothesis that words are stored in some dependent manner.

The present study was designed to extend the findings of Hudson (1969), using a paradigm similar to that of Earhard (1969). Specifically, the hypothesis was that Ss would show a drop in recall on the trial in which information about the categorical nature of the words was given but that on subsequent trials the recall would increase relative to a control group, as would the clustering index.

\section{SUBJECTS}

The Ss were 50 student volunteers from Mississippi State University.

\section{MATERIALS}

Thirty-two words were selected from the Underwood \& Richardson (1956) norms, eight words from each of the categoriesround, white, smelly, and small. The particular words used were the same as the low-variability list of Hudson (1969). A Stowe memory drum was used for word presentation.

\section{PROCEDURE}

Ten Ss were assigned at random to each of three experimental and two control groups. All Ss received six presentation-recall trials. The independent variable was the trial during which information was given. The three experimental groups were given the information on Trial 2, Trial 4, or Trial 6 and are referred to as Condition 2 , Condition 4 , and Condition 6 . They were given the information between presentation and recall of the indicated trial. One control group was given this information before presentation-recall trials began and will be referred to as Condition 0 . The other control group was never given the information and will be referred to simply as the control group.

All Ss were run individually and were assigned to one of the five groups as they appeared for testing. The words were presented at a 4-sec rate. Six different random orders of the words were used, with the starting order for each $S$ being determined at random. After the words were presented for a given trial, E spoke a three-digit number, and $S$ counted backward by twos from it for $15 \mathrm{sec}$. On a trial in which information was given, this was done in lieu of the number counting and took approximately the same amount of time. On this critical trial the Ss were told that the words could be put into one of four categories and were told the category names. They were also given a card on which the category names were typed and told they could keep it for the remaining trials. Recall time was 2 min on each trial.

RESULTS AND DISCUSSION

The data of primary interest is a 